Revista Iberoamericana, Vol. LXXVII, Núm. 234, Enero-Marzo 2011, 235-240

\title{
MAFALDA: \\ BUENOS AIRES, AÑOS 60
}

POR

David William Foster

Arizona State University

Quisiera pedirles que den un paseo conmigo por las calles de Buenos Aires y por los espacios que transitaba Mafalda en los años en los que Quino la dibujaba. Vean, vamos a doblar esa esquina para entrar en el barrio y, al hacerlo, como en El mago de Oz, seremos transportados a otro mundo. Pero, a diferencia de la aventura de Judy Garland, en la que se pasó del blanco y negro de Kansas al color de Oz, nosotros pasaremos del color del Buenos Aires de hoy, todavía luchando por ser Primer Mundo, al blanco y negro de los primeros años de la Revolución Argentina de los militares a mediados de los años 60 .

Si Mafalda realmente nace unos años antes, digamos, como figura de publicidad, asume su verdadero carácter humano en 1966 con la publicación del primer cuaderno que, extendiéndose hasta el 1973, van a terminar siendo diez cuadernos de legendaria estatura en las crónicas de la historieta nacional. Al seguir por esta avenida y antes de doblar la esquina que nos llevará al corazón del barrio que todavía habita Mafalda en el imaginario argentino, nos cruzaremos en la vereda con varios kioscos que siguen ostentando el conjunto de los diez cuadernos que parecen nunca agotarse. Y posiblemente veamos también Toda Mafalda, librote que reúne el contenido de los diez cuadernos, amén de otro material que se editó aparte. Más de veinte años después de que Quino decidió, como dijo en aquel momento, “mandar a Mafalda de vacaciones”, los cuadernos siguen vendiéndose a lectores que continuán descubriendo en ellos, con excepción de algunos detalles afectados por los años, a un Buenos Aires igual que siempre. Si alguien fuera a dudar de la validez de una consigna tanguística como "Buenos Aires es eterno", sólo tiene que repasar las tiras de Quino para entender cómo, en el fondo, en una sociedad como la porteña hay cosas que nunca cambian.

Sin embargo, el Buenos Aires de los años sesenta dista mucho del Buenos Aires de hoy, y valga el truco óptico para recalcar las distancias. Cuando yo llegué a Buenos Aires en el 67, justo un 9 de julio en el que se celebraba el primer aniversario del golpe del General Juan Carlos Onganía y confrères, entendía que había llegado, si no al fin del universo, por lo menos a otro planeta. Y aunque luego comprendí cómo muchas cosas tenían que ver con el impacto de la dictadura (la sedicente Noche de los Bastones Largos 
del 29 de julio de 1966 ya había trastornado, por ejemplo, el ámbito universitario en el que yo me iba a desempeñar como profesor Fulbright), era evidente que Buenos Aires todavía vivía una vida casi provinciana, por lo menos en comparación con los cambios ejercidos en USA en los aciagos años 60. Como dijera Susanita en un momento, "iQué suerte que el mundo está tan lejos”.

De hecho, una dimensión del excepcionalismo argentino tenía, por lo menos en ese entonces, que ver con esa idea de que el mundo estaba tan lejos y que, si el resto de la Argentina era, irremediablemente, latinoamericana, Buenos Aires vivía detenido en el tiempo, como en uno de esos time warps de la ciencia ficción. Por ejemplo, aunque Mafalda y amigos se quejan de la invasión en plaza de los productos extranjeros -ante su embate, Felipe confiesa no ocurrírsele nada para el deber escolar sobre la realidad nacional-, el simple hecho es que los militares todavía no habían descubierto el curro que podría representar el manejo de la Aduana con el alud de las importaciones: eso vendría en la siguiente década con la política de la "plata dulce" y del "Deme dos" impuesta por otra junta. En su mayoría, las importaciones eran clandestinas y el común de la gente o se conformaba con lo que había o se organizaba para tener alguna fuente de compra bajo el poncho. Un frasco de Revlon importado valía, para muchas mujeres, oro molido y la moda, en este detalle, constituía una partición de las aguas: o una salía a la calle con un esmalte cual pintura de planchas de barco naval, o con una las uñas pintadas con un producto yanqui. Para los hombres, la cuestión era tener acceso a un par de pantalones con ziper para no tener que estar siempre lidiando con una bragueta de botones de la época de Eduardo VI (Cortázar se burlará del imperativo de este aggiornamento, en lo que a la ropa de los hombres respectaba, con una crónica sobre los peligros del cierre relámpago de la bragueta masculina).

Uno de los motivos recurrentes en Mafalda es el almacén de barrio, signado en la historieta por el establecimiento del que es dueño el padre de Manolo, un bruto inmigrante español que le comunica a su hijo los principios del capitalismo salvaje, para que el hijo, paradigmática astilla del palo de su progenitor, sueñe con una cadena de supermercados, Don Manolo’s, que le harán la debida competencia a la cadena de Rockefeller que recién estaba comenzando a entrar en el país. Manolo sabe el valor icónico del posesivo inglés, aunque siempre escribe la ese al revés... No me acuerdo si la Coca Cola ya había entrado en la Argentina para esas fechas, pero sí me acuerdo de que uno no podía comprar nada en frasco sin abonar un depósito por el mismo, a cambio de una anotación, en cualquier pedazo arrancado de papel o de cartón, del valor del mismo. Como terminé adicto al yogur Kasdorff (el de la Martona también era rico), llegué a ser dueño de tantos anotados de depósito que podría haber formado una baraja con ellos, porque simplemente no tenía el hábito de cambiarlos por nuevos frascos -hasta que la señora del portero quedó horrorizada de tanto frasco de vidrio que estaba tirando a la basura en contravención de la economía nacional. Almacén Don Manolo (es decir, en su versión primitiva, como almacén de barrio y no unidad

\footnotetext{
\begin{tabular}{l} 
Revista Iberoamericana, Vol. LXXVII, Núm. 234, Enero-Marzo 2011, $235-240$ \\
\hline ISSN 0034-9631 (Impreso)
\end{tabular}
} 
piloto de la cadena con la que soñaba el amiguito de Mafalda), tal como aparece, junto con otros negocios, pero en grado menor, nos sirve para entender mucho sobre la vida doméstica de Buenos Aires de ese entonces, especialmente los rituales de la comida, fresca, casera y casi exclusivamente de cuño nacional. Uno sabía que existía una tienda de ultramarinos - es decir, productos importados-donde se podía comprar un frasco de Skippy’s si llegaba a tener urgencias paladares como las de Horacio Oliveira en Rayuela, que se desvía por un paquete de mate y una lata de dulce de leche. Pero nunca llegué a tener semejantes urgencias, tan afanado estaba en experimentar todas las comidas que se podían acompañar con una cucharada de dulce de leche, fuera o no, como decían con orgullo las cocineras, un invento argentino. No he inventariado toda la extensión de la comida en las tiras de Mafalda, pero ya sé que valdrá la pena hacerlo como una merecida tarea de investigación cultural.

Siempre he pensado que el barrio de Mafalda tiene que haber sido allá por Caballito -es decir, Rivadavia al 5500, donde está la Estación Primera Junta de la Línea Adel Subte (Subterráneos de Buenos Aires, hoy, privatizados bajo el nombre de Metrovías)-. Como los nombres de las calles cambian de uno u otro lado de Rivadavia, bien Mafalda podría haber vivido por Centenera (lado sur) o por Rojas (lado norte). El norte era siempre más clase media que el proletariado sur de Buenos Aires y la familia de Mafalda tenía sus aspiraciones clasemedieras, con propiedad horizontal y todo: un lindo departamentito que le permitía a Mafalda tener su cuarto propio por cuya ventana se podía ver la afloración de antenas en las azoteas en una época en que tener un televisor en el livingcomedor era definitivamente una marca de estatus, lo mismo que tener un Citroën, de esos que se decía se desarmaban en cinco minutos con un abrelatas: hay una serie de tiras sobre el momento en que el papá de Mafalda puede comprar el suyo. Como la plaza es tan importante en el mundo de Mafalda, habría que mover una ficha en el plano de Buenos Aires para acercar la probable residencia de ella, Guille y los amiguitos a las inmediaciones de uno de los más de 600 parques y plazas que embellecen la ciudad.

El Buenos Aires de Mafalda era todavía una ciudad muy chata. Hay que recordar que la topografía de la ciudad es relativamente plana y todavía había pocos edificios altos: los militares todavía no habían comenzado a construir monolitos en su propio honor, como Catalinas y varios fastuosos edificios de departamentos para el uso exclusivo de ellos. Aunque Buenos Aires permanece relativamente chata (sólo hay que compararlo con São Paulo, por ejemplo), la planta de rascacielos ha crecido considerablemente, especialmente en la city y en la zona del nuevo barrio de Puerto Madero, uno de los grandes proyectos del neoliberalismo del que Mafalda hubiera tenido mucho que decir si Quino la hubiera dejado volver de sus vacaciones; de todos modos, Quino comenta mucho sobre el neoliberalismo en sus dibujos sueltos de los años 90.

En los años 60, Buenos Aires todavía no tenía autopistas (el viaje al aeropuerto internacional de Ezeiza era interminable), pero sí tenía incineradores que daban a la ciudad su toque londinense victoriano que quería decir que la bandera nacional era sólo

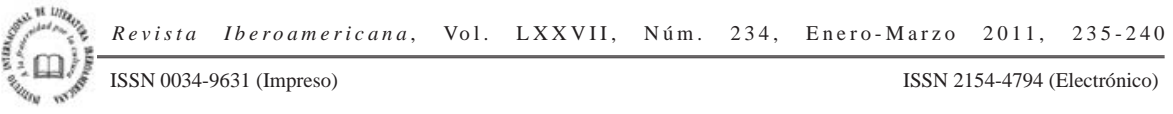


blanco y azul celeste en el abstracto, siendo gris y azul gris en realidad, por no decir prontamente deshilachada por el embiste de las sustancias químicas que chorreaban día y noche las chimeneas de los edificios. Como la gente todavía se dejaba regir por un estricto código formal en la vestimenta, la rigurosa camisa blanca de los hombres (ni pensar ponerse otro color) quedaba asquerosa de manchada en el cuello y en los puños cinco minutos tras salir de la casa: como decía en una tira el papá de Mafalda antes de arreglarse cuidadosamente para salir a trabajar, al llegar a abrir la puerta de su edificio de departamentos: "Aquí es donde la cosa deja de ser como en los avisos". No es de admirarse que la mamá de Mafalda se pusiera en particular agria al hacer el lavado y planchado, con semejante combinación de polución y códigos a lo Carreño: uno tenía que ponerse saco y corbata hasta en verano para ir al cine. Y no hablemos de los guardapolvos blancos (no siempre debidamente almildonados) que estudiantes y maestros gastaban en escuelas y colegios, norma que se extendía también a la mayoría de los funcionarios públicos de menor rango. Mafalda se queja reiteradamente de las arbitrariedades formalistas de su mundo, pero era gritar en el desierto: si su mamá se resignaba a cumplir con ellas, Susanita se vanagloriaba instintivamente de que esas formas y formalidades constituían una de las grandes glorias de la patria.

Al mismo tiempo y a pesar de que, ya en plena época militar, las calles de la ciudad y, en particular, de los barrios céntricos eran seguras, Mafalda y amiguitos deambulan por las calles y por las plazas con una despreocupación ejemplar, desconocida en casi todas las metrópolis latinoamericanas y definitivamente en Nueva York, la cual en los años 60-70 era una ciudad notablemente peligrosa para la seguridad personal; lo mismo Washington, DC y otras ciudades clave de Estados Unidos. La libertad de movimiento que luego perturbará ciertas prácticas de la tiranía cuando el neoliberalismo, cuya dinámica de empobrecimiento generará un inaudito nivel de asaltos, atracos y asesinatos en Buenos Aires a plena luz del día, era una de las primeras cosas que llamaban la atención al adentrarse uno en el mundo de Mafalda y compañía. Se suele comparar Mafalda, erróneamente, con Peanuts/Rabanitos de Charles Schultz. Aun cuando la comparación fuese válida, igual llamaría mucho la atención el hecho de que Charlie y amiguitos no "van a la calle" como es el caso cotidiano en el mundo que representa Quino; a lo sumo, se limitan al jardín de la casa o al campo de recreo del colegio. El grado en que el mundo material, el vivir diario y el natural trajín de la vida aparecen en Mafalda es una de las razones por las que la historieta tiene un alto valor pedagógico: se ve -y por ende- se siente el mundo real de Buenos Aires en casi cada tira, $\mathrm{y}$ hasta los detalles nimios de esta vida cotidiana dan pie para hablar de una amplia gama de lo que significa vivir ahí. Abro Toda Mafalda al azar y veo cómo se celebra una comida familiar, cómo son las normas de urbanidad en el espacio público, cómo está dispuesto el colegio (Mafalda insiste en que el Ministerio de Educación sabe imponer una norma de decadencia arquitectónica uniforme), cómo es el diseño visual de un barrio porteño y mucho más que le puede servir a uno como punto de partida para una exposición detallada.

\footnotetext{
Revista Iberoamericana, Vol. LXXVII, Núm. 234,
ISSN 0034-9631 (Impreso)
} 
Cuando me fui de Buenos Aires en diciembre de 1967, llevaba en mi equipaje (entre, claro, una enorme cantidad de otros libros, discos, revistas y similares) el único número publicado de Mafalda que se podía conseguir en ese momento, que era el \#2 (editado en septiembre de ese año). El primer cuaderno, editado a principios de 1966, se había agotado y no fue hasta el siguiente viaje que lo pude conseguir: ya Mafalda se había convertido en uno de los mayores éxitos editoriales de toda la historia argentina. Los pormenores de mi reintegración a la vida norteamericana me hicieron demorar en volver sobre el material que había traído de Buenos Aires, pero en algún momento comencé a revisarlo bien y Mafalda volvió a encantarme como lo había hecho cuando la conocí en la Argentina, más que nada, quiero recordar, porque en esa época me devolvía a las calles y los entornos porteños -es decir, me provocaba inevitablemente una nostalgia tremenda.

Creo que es en Mafalda en quien cae la responsabilidad de que terminara afirmándome como argentinista, cosa que no era cuando acepté enseñar en Buenos Aires: iba a ser nada más que una aventura de juventud. Sin embargo, Mafalda me hizo sentir profundamente la ciudad de Buenos Aires y habría sido porque todavía yo no tenía suficiente conocimiento cultural como para sentir lo mismo en Borges, Marechal, Cortázar, Sábato, Gambaro y otros. Eso vino después. Pero al principio, Mafalda fue mi hilo de Ariadna en el laberinto de Buenos Aires. Siempre ha sido lo mismo conmigo: un texto determinado me lleva, lateralmente, a profundizar en otras producciones, y eso fue lo que pasó con los cuadernos de Mafalda (que, lógico, terminé teniendo todos y las varias otras recopilaciones también). Me dejé llevar por el arte gráfico, especialmente por el humorismo y el formato de la historieta y, décadas después, tras madurar muchos conocimientos, terminé desembocando todo en un libro que algunos han sabido apreciar como pionero en el tema, por lo menos en cuanto a América Latina. Como en el momento, privaban las aproximaciones más semióticas, me dejé llevar por el lado del análisis del texto, aunque resarcí las limitaciones en cuanto al análisis socio-ideológico en reprises posteriores, especialmente en lo que a Mafalda se refiere, hasta el punto de merecer ella un capítulo entero como parte de un libro que publiqué hace un par de años sobre la ciudad de Buenos Aires y su producción cultural.

Estoy repitiendo, más de cuatro décadas después, el llamado “efecto Mafalda” con la novela gráfica. Descubrí por casualidad las narraciones que Fábio Moon y Gabriela Bá publicaron directamente en inglés sobre la ciudad de São Paulo, en cuya producción cultural vengo trabajando últimamente, y me han llevado a su material original en portugués y al tema en general de la novela gráfica, tema sobre el que no existe casi nada en cuanto a análisis interpretativo. Por ejemplo, se ha escrito bastante sobre $E l$ Eternauta de Héctor Oesterheld, pero casi nada que precise cómo funciona este texto tan señero de los años de plomo en la Argentina. He descubierto que hay un mercado en inglés para la novela gráfica latinoamericana: muchos de los cuadernos de Carlos Trillo, el de Las puertitas del Sr. López, han sido publicados en inglés en USA y hay ahí todo

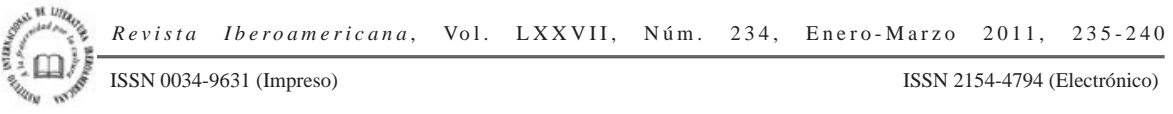


un subtema en cuanto a la globalización de la cultura latinoamericana. Esto ya no es el mundo ameno de Mafalda -por mucho que Quino la hubiera utilizado para decir cosas tajantes sobre la sociedad argentina, su arte no deja de ser profundamente ameno- y el universo de la novela gráfica suele ser tenebroso, siniestro y tremendamente violento (y no se puede prescindir de contemplar la cuestión del sexismo y otras "incorrecciones políticas” en este tipo de producción artística). Insisto y reitero: es Mafalda quien tiene la culpa de todo esto: si un día no hubiera caminado su barrio, si un día no hubiera comprado, casi por casualidad, ese primer cuaderno (es decir, el \#2), quién sabe, hubiera terminando escribiendo el gran libro que hace falta sobre Marechal. No, mejor nunca haber tenido otro destino que dedicarme a leer las tiras de Mafalda.

Y bueno, espero que les haya gustado nuestro pequeño paseo por su barrio. 